\title{
Rail Rate Mediation and Arbitration for Grain Shippers
}

\author{
Marvin Prater • Adam Sparger
}

\section{Summary}

Transportation costs have a direct impact on agricultural producers' profits. Agricultural producers in remote areas have few transportation alternatives, and the price they receive for their products is net of transportation and other marketing and handling costs. When producers and marketers of agricultural products believe the rates they are paying for transportation are too high or uncompetitive, they need access to a dispute-settlement mechanism that is fair, easily understood, accessible, and affordable.

Agricultural shippers believe the formal procedures for challenging unreasonable rail freight rates available through the Surface Transportation Board (STB) are too lengthy and expensive, with the risk not being worth the reward, effectively preventing them from accessing meaningful rate relief. Also, although affected by rail rates, agricultural producers do not have access to STB rate-challenge procedures because they typically do not ship their products to the ultimate consumer, but rather sell them to agribusinesses that arrange for transportation to the final customer.

Mediation and arbitration of agricultural rail rates offer alternatives to formal STB procedures. A less formal rail rate mediation/arbitration system could potentially provide a fairer and lower cost approach to challenging rail rates. The Montana Grain Growers Association, Montana Farm Bureau Federation, and BNSF Railway Company (BNSF) have developed rail rate mediation/arbitration procedures that can be accessed by producers. Although this system is a step forward, it is limited to only one State and one railroad; no other major railroad thus far has been willing to arbitrate rail rates.

A national-level rail rate mediation/arbitration system that is simple and cost-effective is needed to provide a fair and impartial forum for all grain producers and shippers.

\section{Introduction}

The United States has invested in a transportation infrastructure-truck, barge, and rail —-that gives its agricultural producers a competitive advantage in transportation costs. Even so, higher transportation costs in any given situation can damage the competitive position of U.S. agricultural products in the highly competitive export markets, as can the cost of production at the farm level. The ability to export surplus grain production is extremely important because U.S. farmers produce much more than can be consumed domestically. The ability to export excess supply supports 
domestic grain and agricultural product prices, provides jobs, and enhances the vitality of rural economies. The rates agricultural shippers pay for transportation can facilitate or inhibit American competitiveness in world agricultural markets, which can directly degrade the strength of local rural economies.

Railroad volumes and business also hinge on competitiveness in world and domestic markets. Depending on the particular market and geographic location, agricultural shippers may have a choice among transportation carriers or modes. On the other hand, other commodities compete with agricultural traffic for rail capacity, which can influence railroads' offered rates.

Because markets do not respond competitively from every origin at all times, however, producers and shippers may sometimes view the rates they are paying for transportation as excessive or uncompetitive. With transportation costs integral to profit, producers and shippers need access to fair, cost-effective processes to challenge rail rates they believe to be unreasonable.

Under the Staggers Rail Act of $1980,{ }^{1}$ agricultural and other shippers may challenge rail rates that are 180 percent or greater of the revenue-to-variable cost ratios of carriers providing the service. Currently, agricultural shippers may challenge rail rates through a formal rail-rate appeals process governed by the Surface Transportation Board. They also may submit a rail-rate dispute to the National Grain and Feed Association (NGFA) rail arbitration system. But under the NGFA Rail Arbitration Rules, ${ }^{2}$ either the shipper or the carrier must be an NGFA member company, and both of the involved parties must agree to arbitrate the rail rate case. A third option for producers shipping through facilities in Montana that are served by BNSF Railway is the rail-rate mediation/arbitration mechanism established by the BNSF and some farm organizations.

\section{Rate Appeals Procedures}

There are currently three rate appeals procedures available to shippers through the STB. The first procedure is known as the Stand-Alone Cost (SAC) test. Under the SAC test, a shipper has to design an optimally efficient, hypothetical railroad to serve the traffic that includes the route used by the shipper. The shipper then develops a hypothetical rate used to judge the reasonableness of the actual rate being charged. This hypothetical rate simulates the rate which would prevail in a competitive market. However, the costs and complexity of a SAC test make it inaccessible to all but the biggest shippers who must pay, on average, $\$ 5$ million or more to litigate such a case.

The second procedure was designed for medium-size rate disputes. It is known as the Simplified-SAC test and is a scaled-down version of the original SAC test, using simplifying assumptions to judge the reasonableness of the challenged rate. Though it is less expensive than the Stand-Alone Cost procedure, the Simplified-SAC procedure still requires more than $\$ 2$ million in legal and consulting costs to pursue.

The third procedure, known as the Three-Benchmark test, was designed as a less costly alternative to the SAC test to be used in small rate cases. With this test, the reasonableness of the challenged rate is determined by comparing the markup (difference between revenue and variable cost) for the challenged rate to three different comparable markups. This shows whether the challenged rate markup is reasonable compared to other markups. The cost of appealing rail rates using the Three-Benchmark procedure ranges from $\$ 250,000$ to $\$ 500,000$, and the limitation on rate relief is $\$ 4$ million over a 5 -year period. ${ }^{3}$

\footnotetext{
Staggers Rail Act of 1980, Public Law 96-448, Title Il-Railroad Rates and Inter-Carrier Practices, §10701a.

2 National Grain and Feed Association. "Trade Rules and Arbitration, Arbitration System." http://www.ngfa.org/trade-rules-arbitration/arbitration/, (February 5, 2014)

3 STB Decision 42980, July 18, 2013, Docket No. Ex Parte 715, Rate Regulation Reforms.
} 
Agricultural shippers are in need of a rate-challenge procedure that is timelier and less expensive than these rate appeals procedures. Many agricultural shippers have found these rate-challenge procedures too lengthy and expensive, effectively preventing them from accessing rate relief. Although chemical companies have successfully used the Three-Benchmark Procedures, no agricultural shipper has appealed rates using them. U.S. Magnesium, a producer of chlorine, is the only firm to file a rate complaint using the Simplified-SAC procedures, but settled the case before an STB decision was rendered. ${ }^{4}$

\section{Mediation and Arbitration}

Mediation and arbitration offer alternatives to the rate-challenge procedures at the STB. Mediation is an informal process in which the parties discuss issues in dispute with a mediator who assists them in resolving the dispute. The outcomes of mediation are not binding. Arbitration is more formal than mediation, but is still a relatively informal process compared to formal STB procedures. Arbitration is generally binding on the parties, in which the parties in a dispute present written and/or oral arguments before an arbitration panel of neutral qualified third-party arbitrators with expertise in the subject matter of the dispute. The quality of the decisions in arbitration is strongly dependent on the objectivity and qualifications of the selected arbitrators.

Arbitration involving grain-shipper rail-rate appeals would operate most effectively with a panel of three arbitrators who collectively have strong backgrounds in arbitration procedures, grain merchandising, and rail transportation. A panel of three arbitrators is generally preferred because it improves the likelihood of well-reasoned opinions, enhances the balance and fairness with which the system is viewed, and reduces the potential for inadvertent errors. All of these reasons are especially important given that there are limited rights for court appeals under arbitration.

Unlike a court case, an arbitration decision does not set precedent. However, by agreeing to participate in arbitration, the parties agree to be bound by the arbitral decision with limited appeals rights. Thus, a desirable arbitration agreement would provide for an appeals process that broadly allows either party to appeal an arbitrated decision in addition to necessary instances involving a clear abuse of an arbitrator's authority or discretion. Without an effective avenue for appeal within the arbitration agreement, parties may not be as willing to enter arbitration proceedings because the court system generally will not vacate arbitration decisions. When an arbitration appeal to the court system occurs, the appellate court will typically look at the process of arbitration and the way in which the rules of law were applied to determine whether the proceeding was fair, but will generally not alter the arbitrator's finding of facts or decision unless impropriety, such as clear arbitral bias, is present.

If parties are to make use of an arbitration system, there must be assurances of fairness, neutrality, and openness to foster an atmosphere of trust. Publishing the decisions-excluding proprietary and confidential business information-is essential for providing transparency, building trust in individual arbitrators, and demonstrating a commitment to neutrality. In addition, publicly published decisions can discourage extreme positions, encourage voluntary settlement, and create incentives for arbitrators to render thoughtful, well-reasoned decisions. Arbitration processes that are perceived as accessible and fair by both parties are also likely to encourage the parties to try to resolve the dispute through direct discussions, thereby preserving business relationships.

A major benefit of arbitration is that it has the potential to offer less time-consuming and lower cost rail-rate challenge procedures than the formal STB process. One of the most important aspects of arbitration is the direct business discussions it encourages, facilitating informal mediation of many issues before they require more formal arbitration. The Montana-BNSF Railway arbitration system only charges each party an initial \$400 case management fee to initiate a case. Additional fees are determined by the fee schedule of the administering body, the Judicial Arbitration and Mediation Services (JAMS).

4 U.S. Magnesium v. Union Pacific Railroad, Surface Transportation Board, NOR 42115 and NOR 42116. The cases were initiated on June 25, 2009, and terminated on March 24, 2010. 
Similarly, the STB and NGFA have arbitration systems for resolving commercial disputes between shippers and participating railroads. The NGFA arbitration system, established in the late 1890s, has a long history of successful resolution of disputes. The fee structure for NGFA rail disputes arbitration is:

\begin{tabular}{|l|l|}
\hline Up to $\$ 100,000$ claim & $\$ 400$, plus $1 \%$ of the claim \\
\hline$\$ 100,001$ to $\$ 500,000$ claim & $\$ 900$, plus $1 / 2 \%$ of the claim \\
\hline More than $\$ 500,001$ claim & $\$ 2,150$, plus $1 / 4 \%$ of the claim \\
\hline Any claim & Maximum fee of $\$ 10,000$ \\
\hline
\end{tabular}

However, the fees cited in these examples do not include the possible costs of a consultant and/or lawyer that the parties may decide to use to help prepare the case.

\section{Montana-BNSF Mediation/Arbitration System}

The mediation/arbitration system between producers in Montana and the BNSF Railway is the only one that can be used to mediate or arbitrate rail rates. BNSF does not have any current plans to enter into other bilateral arbitration agreements, but it is open to reviewing and discussing other voluntary arbitration proposals.

The Montana-BNSF mediation/arbitration system was started January 30, 2009, and is conducted through the Montana Grain Growers Association (MGGA) and the Montana Farm Bureau Federation (MFBF). It is administered by JAMS and modeled after the NGFA's arbitration rules. No other major railroad thus far has been willing to arbitrate rail rates.

The Montana-BNSF arbitration system uses three mutually agreed-upon arbitrators drawn from a pool of eligible arbitrators. If the parties cannot agree on three arbitrators, the claimant chooses one, BNSF chooses one, and the remaining arbitrator is chosen by both parties.

The system is unique in that it allows grain producers, rather than the grain elevator shipping the grain, to make claims. The advantage of this provision is that the grain producer is generally the party that can incur the most harm from rail rates believed to be excessive, since transportation costs are reflected in the price paid to the farmer. By contrast, the elevator's main concern may be that its rail rates are comparable to other elevators in the region so that it does not become uncompetitive.

Eligibility is limited to those producers shipping wheat or barley more than 250 miles on BNSF and is restricted to shipments having a revenue-to-variable cost ratio (R/VC) higher than 180 for non-shuttle shippers and a R/VC higher than 195 for shuttle shippers. The R/VC is determined using the STB Uniform Rail Costing System. Arbitrators are also limited to ruling on the tariff rate, not on the fuel surcharges or other accessorial charges that can add significantly to the cost of rail service. The fuel surcharge, however, is included in mediation discussions. Finally, relief would not be granted in the event a truck rate is lower than the BNSF rate, even though the truck rate would be uneconomic over longer distances or the lower price may be given only when the trucking firm needs a backhaul. Any relief obtained by the producer is effective for no more than 1 year from the award and 14 months prior to the commencement of the arbitration process. 
In December 2009, a case filed by a Shelby, MT, producer was successfully mediated. The rate at issue was for wheat shipments from Shelby to export facilities near Portland, Oregon. A majority of Montana's wheat crop each year is loaded on vessels at the mouth of the Columbia River, and nearly all of the wheat is transported from origin to destination by BNSF. As a result of this mediation, BNSF lowered the rail rate by $\$ 165$ per railcar (about 4.5 cents per bushel). In addition, BNSF reduced rates, to a smaller extent, for shuttle loaders east of Shelby and on its Northern line in order to preserve current market relationships among elevators.

Even though the Montana-BNSF system has received some praise from agricultural and shipper interests, it is not without its opponents. Montana Attorney General Steve Bullock criticized the Montana-BNSF arbitration system as being unlikely to provide meaningful relief to shippers. ${ }^{5}$

\section{Conclusions}

There is a need for agricultural producers and shippers to have access to a fair, timely and affordable method for challenging rates believed to be unreasonable. The current STB rules governing SAC, Simplified-SAC, and ThreeBenchmark rate appeals have not been feasible for agricultural shippers. Additionally, the STB rate-challenge procedures do not give agricultural producers an opportunity to bring a rail rate case; only the grain elevator shipping the grain may make a claim.

Arbitration of agricultural rail rates potentially promises a more expeditious, fairer, and lower cost way of challenging high rail rates. All the country's grain producers and shippers deserve a forum and process that is fair, impartial, costeffective, and works for the betterment of both shippers and major railroads. Major railroads in addition to BNSF should be encouraged to participate in a similar program that is national in scope.

5 Letter to BNSF from Montana Attorney General Steve Bullock, August 17, 2009. 


\section{Page 1 photo credit:}

- Jerry Huddleston

\section{Preferred citation:}

Prater, Marvin, and Adam Sparger, Rail Rate Mediation and Arbitration for Grain Shippers. U.S. Department of Agriculture, March 2014. Web. <http://dx.doi.org/10.9752/TS151.03-2014>

For more information, contact Marvin.Prater@ams.usda.gov or Adam.Sparger@ams.usda.gov.

The U.S. Department of Agriculture (USDA) prohibits discrimination against its customers. If you believe you experienced discrimination when obtaining services from USDA, participating in a USDA program, or participating in a program that receives financial assistance from USDA, you may file a complaint with USDA. Information about how to file a discrimination complaint is available from the Office of the Assistant Secretary for Civil Rights. To file a complaint of discrimination, complete, sign and mail a program discrimination complaint form, available at any USDA office location or online at www.ascr.usda.gov, or write to: USDA, Office of the Assistant Secretary for Civil Rights, 1400 Independence Avenue, S.W., Washington, D.C. 20250-9410. Or call toll free at (866) 632-9992 (voice) to obtain additional information, the appropriate office or to request documents. Individuals who are deaf, hard of hearing or have speech disabilities may contact USDA through the Federal Relay service at (800) 877-8339 or (800) 845-6136 (in Spanish). USDA is an equal opportunity provider, employer and lender. Persons with disabilities who require alternative means for communication of program information (e.g., Braille, large print, audiotape, etc.) should contact USDA's TARGET Center at (202) 720-2600 (voice and TDD). 